\title{
Cannabidiol, a Cannabis sativa constituent, as an antipsychotic drug
}

\footnotetext{
A.W. Zuardi²,

J.A.S. Crippa ${ }^{2}$,

J.E.C. Hallak²,

F.A. Moreira ${ }^{1}$ and

F.S. Guimarães ${ }^{1}$
}

\author{
'Departamento de Farmacologia, \\ ${ }^{2}$ Departamento de Neurologia, Psiquiatria e Psicologia Médica, \\ Faculdade de Medicina de Ribeirão Preto, \\ Universidade de São Paulo, Ribeirão Preto, SP, Brasil
}

\section{Correspondence \\ A.W. Zuardi \\ Departamento de Neurologia, \\ Psiquiatria e Psicologia Médica \\ FMRP, USP \\ Av. Bandeirantes, 3900 \\ 14049-900 Ribeirão Preto, SP \\ Brasil \\ E-mail: awzuardi@fmrp.usp.br}

Several studies reviewed here were

supported by FAPESP and CNPq.

Received August 9, 2005

Accepted December 14, 2005

\begin{abstract}
A high dose of $\Delta^{9}$-tetrahydrocannabinol, the main Cannabis sativa (cannabis) component, induces anxiety and psychotic-like symptoms in healthy volunteers. These effects of $\Delta^{9}$-tetrahydrocannabinol are significantly reduced by cannabidiol (CBD), a cannabis constituent which is devoid of the typical effects of the plant. This observation led us to suspect that CBD could have anxiolytic and/or antipsychotic actions. Studies in animal models and in healthy volunteers clearly suggest an anxiolytic-like effect of CBD. The antipsychotic-like properties of CBD have been investigated in animal models using behavioral and neurochemical techniques which suggested that CBD has a pharmacological profile similar to that of atypical antipsychotic drugs. The results of two studies on healthy volunteers using perception of binocular depth inversion and ketamine-induced psychotic symptoms supported the proposal of the antipsychotic-like properties of CBD. In addition, open case reports of schizophrenic patients treated with CBD and a preliminary report of a controlled clinical trial comparing CBD with an atypical antipsychotic drug have confirmed that this cannabinoid can be a safe and well-tolerated alternative treatment for schizophrenia. Future studies of CBD in other psychotic conditions such as bipolar disorder and comparative studies of its antipsychotic effects with those produced by clozapine in schizophrenic patients are clearly indicated.
\end{abstract}

\section{Introduction}

The use Cannabis sativa (cannabis) extracts as medicine was described in China and India (1) before the birth of Christ. The therapeutic use of cannabis was introduced in Western medicine in the first half of the 19th century and reached its climax in the last two decades of the same century. At the turn of the century, several pharmaceutical
Key words

- Cannabidiol

- $\Delta^{9}$-Tetrahydrocannabinol

- Cannabinoid

- Anxiety

- Antipsychotic

- Schizophrenia 
able individual responses, the introduction of synthetic and more stable pharmaceutical substitutes such as aspirin, chloral hydrate and barbiturates, the recognition of important adverse effects such as anxiety and cognitive impairment, and the legal restrictions to the use of cannabis-derived medicines (2).

Today this situation has changed considerably. The main active psychotropic constituent of cannabis, $\Delta^{9}$-tetrahydrocannabinol $\left(\Delta^{9}\right.$-THC), was isolated, identified and synthesized in the 1960's. Almost three decades later, cannabinoid receptors in the brain were described and cloned and the endogenous cannabinoids were isolated and identified (3). As a result of these discoveries the interest in cannabis research has remarkably increased. For instance, the number of publications using the key word "brain", compiled by the ISI Web of Knowledge, increased 26 times from 1960-1964 to 20002004 , while the number of publications about 'cannabis' increased 78.5 times during the same period. As a consequence, the research on the use of cannabis as medicine has been renewed.

Although $\Delta^{9}$-THC is commonly accepted as the main factor responsible for the effects of cannabis, several reports have demonstrated that other components of the plant influence its pharmacological activity (4). One of these components is cannabidiol (CBD), which may constitute up to $40 \%$ of cannabis extracts (5) and is devoid of the typical psychological effects of cannabis in humans (6). Studies on the interaction between $\Delta^{9}$-THC and CBD have produced apparently contradictory results (7). Although potentiation of the effects of $\Delta^{9}$-THC has been observed $(8,9)$, this phenomenon probably involves pharmacokinetic interactions since CBD is a potent inhibitor of hepatic drug metabolism (10) and increases $\Delta^{9}$-THC concentrations in the brain (11). Several studies, however, have reported antagonism of the effects of $\Delta^{9}$-THC when both compounds are administered simultaneously to animals
$(12,13)$ or humans $(6,14)$.

CBD $(1 \mathrm{mg} / \mathrm{kg})$ co-administered with $\Delta^{9}$ THC $(0.5 \mathrm{mg} / \mathrm{kg})$ significantly reduced the anxiety and the psychotomimetic symptoms induced by the latter drug in healthy volunteers (6). Since the dose of CBD used in that study did not change $\Delta^{9}$-THC levels in blood (15), it was suggested that CBD blocked the effects of $\Delta^{9}$-THC by some intrinsic pharmacological properties. Actually, when administered alone CBD produced its own effects, including hypnotic (16), anticonvulsive (17), neuroprotective (18), and hormonal (increased corticosterone and cortisol levels) effects $(19,20)$. These effects led to the hypothesis that CBD could have anxiolytic and/or antipsychotic effects.

\section{Anxiolytic effect of cannabidiol}

The anxiolytic properties of CBD has been demonstrated by several pre-clinical studies that employed different paradigms such as the conditioned emotional response (21), the Vogel conflict test (22) and the elevated plus-maze $(23,24)$. In the later study (24), the effective doses of CBD ranged from 2.5 to $10 \mathrm{mg} / \mathrm{kg}$, and the drug produced an inverted U-shaped dose-response curve, the higher doses being no longer effective in rats. This could explain the negative results obtained with high doses of CBD (above $100 \mathrm{mg} / \mathrm{kg}$ ) in a previous study employing the Geller-Seifter conflict test (25).

To evaluate a possible anxiolytic effect of CBD in humans, a double-blind study was conducted on healthy volunteers submitted to a simulation of the public speaking test. CBD (300 mg, po) was compared to ipsapirone $(5 \mathrm{mg})$, diazepam $(10 \mathrm{mg})$ or placebo. The results showed that both CBD and the two other anxiolytic compounds attenuated the anxiety induced by the test (26). The anxiolytic-like effect of CBD in healthy volunteers was also observed in a more recent double-blind study that investigated its effects on regional cerebral blood flow by 
single-photon emission computed tomography. Because the procedure, by itself, can be interpreted as an anxiogenic situation, it permits the evaluation of anxiolytic drugs. CBD induced a clear anxiolytic effect and a pattern of cerebral activity compatible with an anxiolytic activity (27). Therefore, similar to the data obtained in animal models, results from studies on healthy volunteers have strongly suggested an anxiolytic-like effect of CBD.

\section{Antipsychotic effect}

\section{Studies employing animal models}

Animal models used for screening antipsychotic drugs are based on the neurochemical hypothesis of schizophrenia, involving mainly the neurotransmitters dopamine and glutamate (28).

Antagonism of dopamine $\mathrm{D}_{2}$ receptors may be a common feature of most clinically effective antipsychotic drugs, especially those active against hallucinations and delusions (29). The dopamine-based models usually employ apomorphine, a direct agonist, or amphetamine, a drug that increases the release of this neurotransmitter and blocks its re-uptake. Another common effect of antipsychotic drugs is hyperprolactinemia that results from the antagonism of $\mathrm{D}_{2}$ receptors on anterior-pituitary mammotrophic cells. These cells are tonically inhibited by dopamine produced in the hypothalamic arcuate nucleus (30). Conventional or typical antipsychotic drugs, especially those with high affinity for $\mathrm{D}_{2}$ receptors (haloperidol being the standard compound), induce motor side effects characterized by a Parkinson-like syndrome. On the contrary, atypical antipsychotic drugs, of which clozapine is the prototype, are therapeutically effective at doses that induce fewer or no Parkinson-like effects (29). The probability of an antipsychotic agent to induce Parkinson-like symptoms may be evaluated in the catalepsy test
(31). Atypical antipsychotics inhibit the stereotypies and hyperlocomotion induced by dopamine agonists at lower doses than those that produce catalepsy.

As a first step in the investigation of possible antipsychotic-like properties of $\mathrm{CBD}$, the drug was compared to haloperidol in rats submitted to dopamine-based models (32). However, blocking $\mathrm{D}_{2}$ receptors is not necessarily the only mechanism for the antipsychotic activity. Several lines of evidence suggest that the glutamatergic N-methyl-Daspartate (NMDA) receptor is involved in the mechanism of action of clozapine (33). The glutamate-based models of schizophrenia employ sub-anesthetic doses of ketamine, a glutamate NMDA receptor antagonist, or its related compound phencyclidine, to induce psychotic symptoms. A more recent study investigated the effects of CBD in both dopamine and glutamate-based models predictive of antipsychotic activity. The study compared the ability of CBD, haloperidol and clozapine to prevent the hyperlocomotion induced by amphetamine or ketamine in mice (34). The results of these two studies are summarized in Table 1.

CBD (15-60 mg/kg), like haloperidol $(0.25-0.5 \mathrm{mg} / \mathrm{kg})$, reduced the apomorphineinduced stereotyped behavior in rats in a dose-related manner. These drugs also increased the plasma levels of prolactin. However, higher doses of CBD were needed (120 and $240 \mathrm{mg} / \mathrm{kg}$ ) to obtain such effects. Moreover, in contrast to haloperidol, CBD did not induce catalepsy, even at doses as high as $480 \mathrm{mg} / \mathrm{kg}$. In agreement with the results obtained in rats, CBD $(15-60 \mathrm{mg} / \mathrm{kg})$ inhibited the hyperlocomotion induced by amphetamine in mice in a dose-related manner. In addition, the drug also attenuated the hyperlocomotion induced by ketamine, expanding its antipsychotic-like effects to a glutamate-based model. As expected, while both haloperidol $(0.15-0.6 \mathrm{mg} / \mathrm{kg})$ and clozapine $(1.25-5.0 \mathrm{mg} / \mathrm{kg})$ inhibited hyperlocomotion, only haloperidol induced cata- 
Table 1. Summary of two studies employing animal models for the screening of antipsychotic drugs, which compared cannabidiol, haloperidol and clozapine in rats (32) and mice (34).

\section{Rats}

\section{Cannabidiol $(\mathrm{mg} / \mathrm{kg})$}

Apomorphine stereotypy (biting) [\% of animals] Prolactin levels $(\mathrm{ng} / \mathrm{mL})$ [mean (SEM)]

Catalepsy time (s) [median]

\section{Haloperidol $(\mathrm{mg} / \mathrm{kg})$}

Apomorphine stereotypy (biting) [\% of animals] Prolactin levels $(\mathrm{ng} / \mathrm{mL})$

[mean (SEM)]

Catalepsy time (s) [median]

\begin{tabular}{|c|c|c|c|c|c|c|c|c|}
\hline 0 & 15 & 30 & 60 & 120 & 240 & 480 & & \\
\hline 83.3 & 83.3 & 50.0 & $16.71^{*}$ & - & - & - & & \\
\hline 4.1 & 11.1 & 12.2 & 13.5 & $29.8^{*}$ & $38.1^{*}$ & - & & \\
\hline$(0.7)$ & $(1.0)$ & $(1.6)$ & $(2.6)$ & (3.1) & (13.5) & & & \\
\hline 150 & - & - & 365 & 214 & 626 & 646 & & \\
\hline 0 & 0.06 & 0.125 & 0.15 & 0.25 & 0.3 & 0.5 & 0.5 & 1.0 \\
\hline 83.3 & - & 83.3 & - & 50.0 & - & $0.0^{*}$ & - & - \\
\hline 3.0 & 14.3 & $28.3^{*}$ & - & $33.3^{*}$ & - & $39.5^{\star}$ & - & - \\
\hline$(1.0)$ & $(4.2)$ & $(3.1)$ & & $(3.0)$ & & $(1.7)$ & & \\
\hline 150 & - & 713 & - & $1684^{*}$ & - & $1408^{*}$ & - & $4737^{*}$ \\
\hline
\end{tabular}

\section{Mice}

\section{Cannabidiol $(\mathrm{mg} / \mathrm{kg})$}

Amphetamine hyperlocomotion distance $(\mathrm{cm})$ [mean (SEM)]

Ketamine hyperlocomotion distance $(\mathrm{cm})$ [mean (SEM)]

Catalepsy time (s) [mean (SEM)]

\section{Haloperidol $(\mathrm{mg} / \mathrm{kg})$}

Amphetamine hyperlocomotion distance (cm) [mean (SEM)]

Ketamine hyperlocomotion distance $(\mathrm{cm})$ [mean (SEM)]

Catalepsy time (s) [mean (SEM)]

\section{Clozapine $(\mathrm{mg} / \mathrm{kg})$}

Amphetamine hyperlocomotion distance $(\mathrm{cm})$ [mean (SEM)]

Ketamine hyperlocomotion distance $(\mathrm{cm})$ [mean (SEM)]

Catalepsy time (s)

[mean (SEM)]

\begin{tabular}{|c|c|c|c|c|c|c|c|c|}
\hline 0 & 15 & 30 & 60 & 120 & 240 & 480 & & \\
\hline 5326 & 4838 & $2689^{*}$ & $1730^{*}$ & - & - & - & & \\
\hline (1160) & (683) & $(383)$ & $(378)$ & & & & & \\
\hline 5154 & 4191 & $3254^{+}$ & 4127 & - & - & - & & \\
\hline$(235)$ & (985) & $(506)$ & $(962)$ & & & & & \\
\hline 8.3 & 2.4 & 4.1 & 3.7 & - & - & - & & \\
\hline$(2.2)$ & $(0.4)$ & $(1.0)$ & (1.3) & & & & & \\
\hline 0 & 0.06 & 0.125 & 0.15 & 0.25 & 0.3 & 0.5 & 0.6 & 1.0 \\
\hline 4111 & - & - & $1039^{\star}$ & - & $804^{*}$ & - & $473^{\star}$ & - \\
\hline$(571)$ & & & $(90)$ & & (166) & & (134) & \\
\hline 5218 & - & - & 3277 & - & $1392^{*}$ & - & $728^{*}$ & - \\
\hline$(561)$ & & & (513) & & (376) & & (197) & \\
\hline 7.7 & - & - & $109.4^{*}$ & - & $108.3^{*}$ & - & 241.4 & - \\
\hline$(4.1)$ & - & - & $(40.5)$ & & (29.6) & & $(30.0)$ & \\
\hline 0 & 1.25 & 2.5 & 5 & & & & & \\
\hline 6437 & 4964 & 3906 & $2883^{*}$ & & & & & \\
\hline (1858) & (1079) & (699) & (938) & & & & & \\
\hline 4852 & $620^{*}$ & $93^{*}$ & $148^{*}$ & & & & & \\
\hline (588) & (200) & (42) & (77) & & & & & \\
\hline 5.3 & 30.1 & 21.7 & 12.6 & & & & & \\
\hline$(1.3)$ & (9.3) & (6.1) & $(6.0)$ & & & & & \\
\hline
\end{tabular}

$\mathrm{N}=6$ to 10 animals per group.

${ }^{*} \mathrm{P}<0.05$ and $+\mathrm{P}<0.10$ compared to the baseline level (Kruskal-Wallis test or ANOVA followed by Duncan test). 
lepsy in this dose range. Therefore, similar to clozapine, CBD did not induce catalepsy at doses that inhibited hyperlocomotion in mice. These results support the view that CBD exhibits a profile similar to that of atypical antipsychotic drugs.

In addition to being tested on behavioral models, typical and atypical antipsychotics may also be distinguished according to their pattern of neural activation. This may be detected by the expression of the proto-oncogene $c$-Fos. For example, haloperidol induces Fos immunoreactivity in the dorsal striatum, probably reflecting its motor side effects, while clozapine induces Fos immunoreactivity in the prefrontal cortex but not in the dorsal striatum (35). The Fos immunoreactivity pattern induced by CBD (120 $\mathrm{mg} / \mathrm{kg}$ ) was compared to that of haloperidol $(1 \mathrm{mg} / \mathrm{kg})$ and clozapine $(20 \mathrm{mg} / \mathrm{kg})$ in rats. Only haloperidol increased Fos immunoreactivity in the dorsal striatum, while both CBD and clozapine, but not haloperidol, induced Fos immunoreactivity in the prefrontal cortex $(36,37)$. These results are consistent with the behavioral data obtained when comparing $\mathrm{CBD}$ with these prototype antipsychotics.

In conclusion, animal models employing behavioral as well as neurochemical techniques suggest that CBD has a pharmacological profile similar to that of an atypical antipsychotic drug.

\section{Safety studies}

Safety studies of CBD were required before human tests. CBD was extensively investigated in laboratory animals to detect possible side or toxic effects (17). Acute CBD administration by the oral, inhalatory or intravenous route did not induce any significant toxic effect in humans (38). In addition, chronic administration of CBD for 30 days to healthy volunteers, at daily doses ranging from 10 to $400 \mathrm{mg}$, failed to induce any significant alteration in neurological, psychiatric or clinical exams (17). Finally, in patients suffering from Huntington's disease, daily doses of CBD (700 mg) for 6 weeks did not induce any toxicity (39). Therefore, confirming results from animal studies, the available clinical data suggest that CBD can be safely administered over a wide dose range.

\section{Clinical use}

In 1848 the French psychiatrist JacquesJoseph Moreau de Tour began to investigate the effects of cannabis. He proposed for the first time the use of the plant as an experimental psychotomimetic (40). Results from a recent study, obtained with more appropriate measurements and scales, agreed with Moreau's observation that $\Delta^{9}$-THC administration induces subjective, cognitive and behavioral changes that resemble endogenous psychosis, suggesting that $\Delta^{9}$-THC can, indeed, be used as an experimental psychotomimetic drug (41).

In 1982, a study investigating a possible interaction between $\Delta^{9}$-THC and CBD in healthy volunteers demonstrated that the latter drug could inhibit $\Delta^{9}$-THC-induced subjective changes that resembled symptoms of psychotic diseases (6) (Figure 1). In the same year, it was observed that patients admitted to a psychiatric hospital in South Africa, after the use of a variety of cannabis virtually devoid of $\mathrm{CBD}$, showed much higher frequency of acute psychotic episodes than in other countries (42). These lines of evidence led to several investigations of a possible antipsychotic effect of CBD.

In order to evaluate the antipsychotic effects of new drugs in healthy volunteers, a useful model is the perception of binocular depth inversion. When a picture is presented separately to each eye, with a slight difference in the angle, it induces a three-dimensional perception. The inversion of this picture from one eye to the other normally 
induces a change in convexity. This change may not be perceived if familiar objects (faces, for example) are presented, with the expected image predominating, which is il-

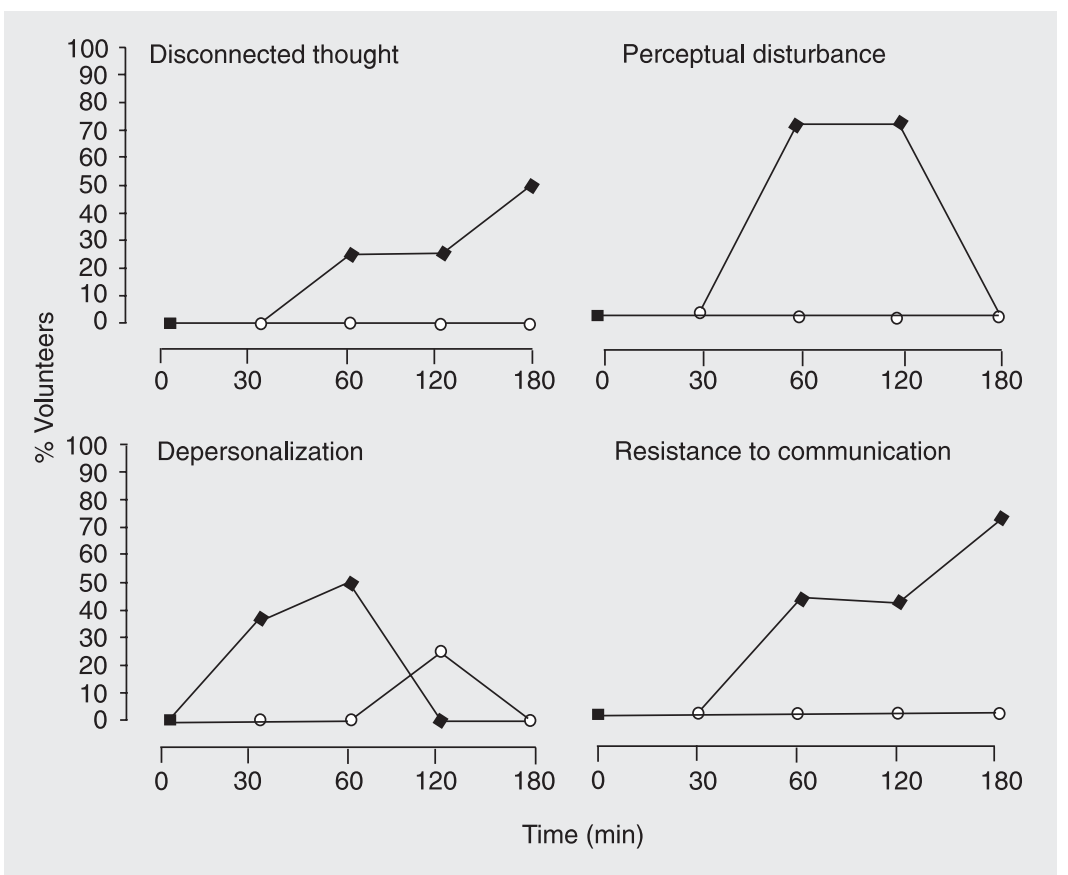

Figure 1. Percentage of healthy volunteers who exhibited psychotic-like effects after the ingestion of $0.5 \mathrm{mg} / \mathrm{kg} \Delta^{9}$-tetrahydrocannabinol ( $\Delta^{9}$-THC; lozenges) and a combination of $0.5 \mathrm{mg} / \mathrm{kg} \Delta^{9}-\mathrm{THC}+1 \mathrm{mg} / \mathrm{kg}$ cannabidiol (circles).

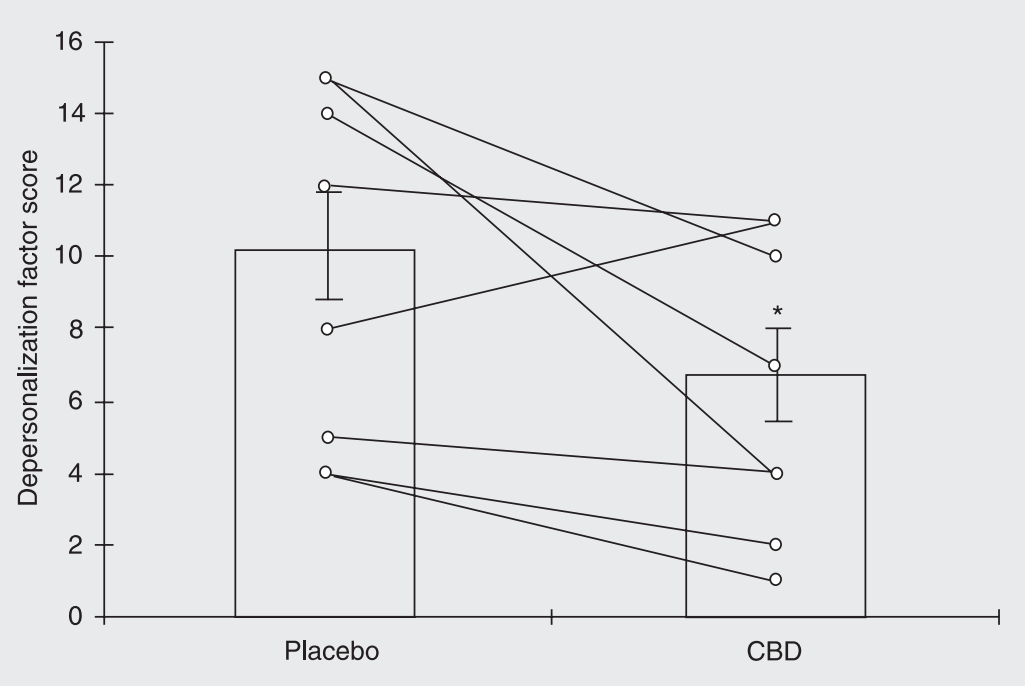

Figure 2. Depersonalization factor scores of the Clinician-Administered Dissociative States Scale for each healthy volunteer (lines) during intravenous ketamine infusion, after oral placebo or cannabidiol (CBD) $(600 \mathrm{mg})$ administration. Bars indicate the mean $\pm \mathrm{SEM}$. ${ }^{*} \mathrm{P}<$ 0.05 compared to placebo (paired $t$-test) for 9 volunteers. lusory. Schizophrenic patients have difficulty in perceiving this illusory image, reporting a more veridical judgment. During antipsychotic treatment, the inverted faces were seen as more illusionary (43). This veridical judgment may also be obtained by the administration of psychotomimetic drugs such as nabilone, a $\Delta^{9}$-THC analogue. In this model, impairment of the perception of the illusory image induced by nabilone was attenuated by $\mathrm{CBD}$, suggesting an antipsychotic-like effect of this compound (44).

Another important model used to evaluate antipsychotic-like activity in healthy volunteers is the administration of sub-anesthetic doses of ketamine. This glutamatebased model induces a psychotic reaction that mimics both positive and negative symptoms of schizophrenia (45). A double-blind crossover procedure was performed to study the effect of CBD in this model (46). Nine healthy volunteers were assigned randomly to the placebo or CBD (600 mg) groups in two experimental sessions separated by a 1week interval. After being submitted to psychiatric assessment scales, the volunteers received placebo orally or the drug and rested for 65 min. An infusion pump was then installed and an intravenous bolus of S-ketamine $(0.26 \mathrm{mg} / \mathrm{kg})$ was administered during 1 min followed by a maintenance dose of $0.25 \mathrm{mg} / \mathrm{kg}$ for $30 \mathrm{~min}$. A Clinician-Administered Dissociative States Scale (CADSS) was applied at the beginning of the sessions and $90 \mathrm{~min}$ after the bolus injection. The volunteers were asked to respond the scale according to the period during which they felt most symptomatic. CBD attenuated the effects of ketamine on the total score of the CADSS and also on each of its factors separately. This effect was significant for the depersonalization factor, further reinforcing the antipsychotic-like properties of CBD (Figure 2).

In view of the safe profile of CBD administration in humans and in laboratory animals, we decided to perform open-label clini- 
cal trials in a reduced number of patients. In 1995, CBD was tested in a case study with a 19-year-old schizophrenic female patient who presented serious side effects after treatment with conventional antipsychotics (47). Following a wash-out period of 4 days this patient received increasing oral doses of CBD dissolved in oil, reaching $1500 \mathrm{mg} / \mathrm{day}$, for 4 weeks. After this period, CBD administration was interrupted and placebo was administered for 4 days. Finally, the treatment was shifted to increasing doses of haloperidol that reached $12.5 \mathrm{mg} /$ day. The psychiatric interviews were video-recorded and the symptoms were assessed by a blinded-psychiatrist using the Brief Psychiatric Rating Scale (BPRS). A significant improvement was observed during CBD treatment, while a worsening was observed when the administration was interrupted. The improvement obtained with CBD was not increased by haloperidol (Figure 3, patient A). Further supporting the safe profile of CBD, no side effects were observed, as assessed by the Ugvalg for Kliniske Undersgelser (UKU) scale (47).

More recently, CBD was administered to three 22- or 23-year-old male patients with a diagnosis of schizophrenia who had not responded to typical antipsychotic drugs (48). They received placebo for 5 days in the hospital followed by CBD from the 6th to the 35th day. After this period, they received placebo for an additional 5 days, followed by olanzapine for at least 15 days. The dose of CBD was increased from 40 up to 1280 $\mathrm{mg} /$ day. The patients were assessed by two psychiatrists, who were blind to the doses administered, using the BPRS and UKU scales. No side effects were observed during CBD treatment, even at the higher dose of $1280 \mathrm{mg} /$ day. A partial improvement was observed in one patient (Figure 3, patient B) while slight or no improvement was observed in the other two (Figure 3, patients $\mathrm{C}$ and $\mathrm{D})$. However, the patients (C and D) were considered to be refractory, since they did not even respond to clozapine, a fact that may explain the lack of CBD effectiveness (48). Figure 3 shows the results obtained with the 4 schizophrenic patients treated so far with CBD. These studies suggest, therefore, that CBD has an antipsychotic-like profile in healthy volunteers and may possess antipsychotic properties in schizophrenic patients, but not in the resistant ones.

Confirming this suggestion, a preliminary report from a 4-week, double-blind controlled clinical trial, using an adequate number of patients and comparing the effects of CBD with amisulpride in acute schizophrenic and schizophreniform psychosis, showed that CBD significantly reduced acute psychotic symptoms after 2 and 4 weeks of treatment when compared to baseline. In this trial CBD did not differ from amisulpride except for a lower incidence of side effects (49).

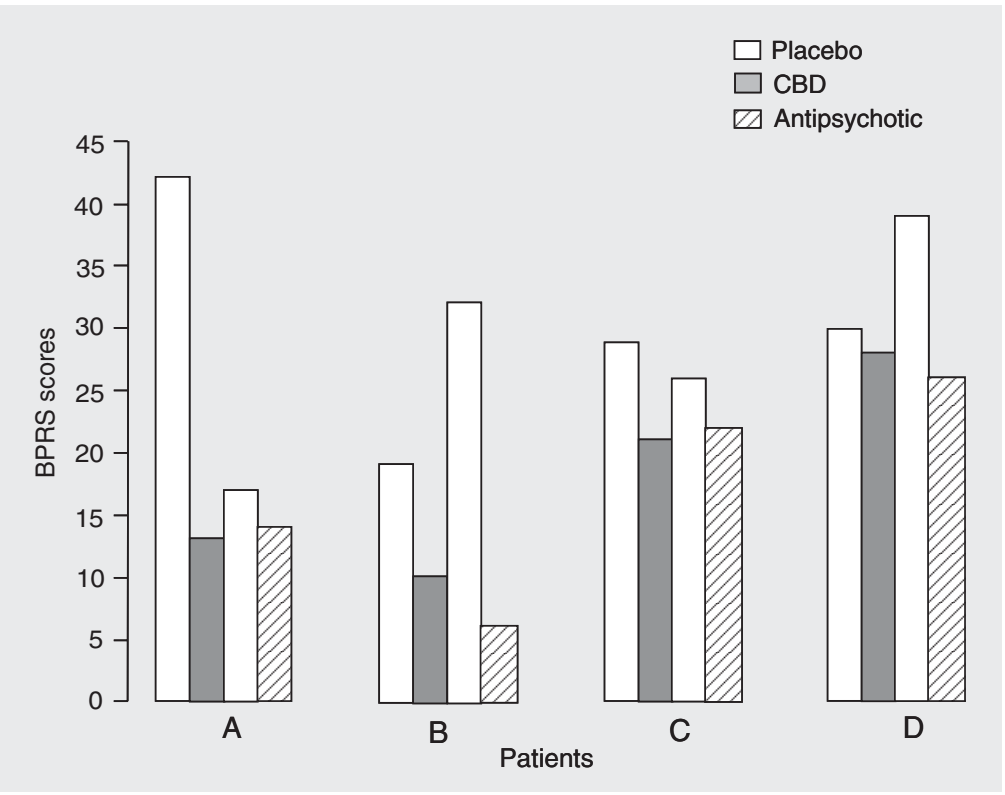

Figure 3. Brief Psychiatric Rating Scale (BPRS) scores for 4 schizophrenic patients treated with cannabidiol (CBD). Patient A received up to $1500 \mathrm{mg} /$ day $C B D$ and patients $B, C$, and $D$ received up to $1280 \mathrm{mg} /$ day. Bars indicate BPRS scores for each schizophrenic patient at the end point after the oral administration of placebo, CBD and a control antipsychotic drug (haloperidol for patient $A$ and olanzapine for patients $B, C$ and D). Placebo was administered before and after CBD treatment. Patient $A$ is a woman who presented serious side effects with typical antipsychotics. Patients B, C, and $\mathrm{D}$ are men previously treated with typical antipsychotics with no response. 
In conclusion, results from pre-clinical and clinical studies suggest that CBD is an effective, safe and well-tolerated alternative treatment for schizophrenic patients. Future trials of this cannabinoid in other psychotic conditions such as bipolar disorder (50) and comparative studies of its antipsychotic effects with those produced by clozapine in schizophrenic patients are clearly needed.

\section{References}

1. Mikuriya TH (1969). Marijuana in medicine: past, present and future. California Medicine, 110: 34-40.

2. Fankhauser M (2002). History of cannabis in Western Medicine. In: Grotenhermen F \& Russo E (Editors), Cannabis and Cannabinoids. The Haworth Integrative Healing Press, New York, 37-51.

3. Martin BR, Mechoulam R \& Razdan RK (1999). Discovery and characterization of endogenous cannabinoids. Life Sciences, 65: 573-595.

4. Carlini EA, Santos M, Claussen V et al. (1970). Structure activity relationship of four tetrahydrocannabinols and the pharmacological activity of five semipurified extracts of Cannabis sativa. Psychopharmacologia, 18: 82-93.

5. Grlie L (1976). A comparative study on some chemical and biological characteristics of various samples of cannabis resin. Bulletin on Narcotics 14: 37-46.

6. Zuardi AW, Shirakawa I, Finkelfarb E et al. (1982). Action of cannabidiol on the anxiety and other effects produced by $\Delta^{9}-\mathrm{THC}$ in normal subjects. Psychopharmacology, 76: 245-250.

7. Karniol IG \& Carlini EA (1973). Pharmacological interaction between cannabidiol and $\Delta^{9}$-tetrahydrocannabinol. Psychopharmacologia, 33: 53-70.

8. Fernandes M, Schabarek A, Coper $\mathrm{H}$ et al. (1974). Modification of $\Delta^{9}$-THC-actions by cannabinol and cannabidiol in the rats. Psychopharmacologia, 38: 329-338.

9. Hollister LE \& Gillespie H (1975). Interactions in man of $\Delta^{9}$-tetrahydrocannabinol, H-cannabinol and cannabidiol. Clinical Pharmacology and Therapeutics, 18: 80-83.

10. Bornhein LM, Borys HK \& Karler R (1981). Effect of cannabidiol on cytochrome P-450 and hexobarbital sleep time. Biochemical Pharmacology, 30: 503-507.

11. Jones G \& Pertwee RG (1972). A metabolic interaction in vivo between cannabidiol and $\Delta^{9}$-tetrahydrocannabinol. British Journal of Pharmacology, 45: 375-377.

12. Davis WM \& Borgen LA (1974). Effects of cannabidiol and $\Delta^{9}$ tetrahydrocannabinol on operant behavior. Research Communications in Chemical Pathology and Pharmacology, 9: 453-462.

13. Zuardi AW, Finkelfarb E, Bueno OFA et al. (1981). Characteristics of the stimulus produced by the mixture of cannabidiol with $\Delta^{9}$-tetrahydrocannabinol. Archives Internationales de Pharmacodynamie et de Therapie, 249: 137-146.

14. Karniol IG, Shirakawa I, Kasinsky N et al. (1974). Cannabidiol interferes with the effect of $\Delta^{9}$-tetrahydrocannabinol in man. European Journal of Pharmacology, 28: 172-177.

15. Agurell S, Carlsson S, Lindgreen JE et al. (1981). Interactions of $\Delta^{1}$ tetrahydrocannabinol with cannabinol and cannabidiol following oral administration in man. Assay of cannabinol and cannabidiol by mass fragmentography. Experientia, 37: 1090-1092.

16. Monti JM (1977). Hypnotic-like effects of cannabidiol in the rats.
Psychopharmacology, 76: 263-265.

17. Cunha J, Carlini EA, Pereira AE et al. (1980). Chronic administration of cannabidiol to healthy volunteers and epileptic patients. Pharmacology, 21: 175-185.

18. Hampson AJ, Grimaldi M, Axelroad J et al. (1998). Cannabidiol and $\Delta^{9}$-tetrahydrocannabinol are neuroprotective antioxidants. Proceedings of the National Academy of Sciences, USA, 95: 8268-8273.

19. Zuardi AW, Teixeira NA \& Karniol IG (1984). Pharmacological interaction of the effects of $\Delta^{9}$-tetrahydrocannabinol and cannabidiol on serum corticosterone levels in rats. Archives Internationales de Pharmacodynamie et de Therapie, 269: 12-19.

20. Zuardi AW, Guimarães FS \& Moreira AC (1993). Effect of cannabidiol on plasma prolactin, growth hormone and cortisol in human volunteers. Brazilian Journal of Medical and Biological Research, 26: 213-217.

21. Zuardi AW \& Karniol IG (1983). Changes in the conditioned emotional response of rats induced by $\Delta^{9}-\mathrm{THC}, \mathrm{CBD}$ and mixture of the two cannabinoids. Arquivos de Biologia e Tecnologia, 26: 391-397.

22. Musty RE, Conti LH \& Mechoulam R (1984). Anxiolytic properties of cannabidiol. In: Harvey DJ (Editor), Marihuana '84. Proceedings of the Oxford Symposium on Cannabis. IRL Press Limited, Oxford, UK, 713-719.

23. Onaivi ES, Green MR \& Martin BR (1990). Pharmacological characterization of cannabinoids in the elevated plus maze. Journal of Pharmacology and Experimental Therapeutics, 253: 1002-1009.

24. Guimarães FS, Chiaretti TM, Graeff FG et al. (1990). Antianxiety effect of cannabidiol in the elevated plus-maze. Psychopharmacology, 100: 558-559.

25. Silveira Filho NG \& Tufik S (1981). Comparative effects between cannabidiol and diazepam on neophobia, food intake and conflict behavior. Research Communications in Psychology, Psychiatry and Behavior, 6: 25-26.

26. Zuardi AW, Cosme RA, Graeff FG et al. (1993). Effects of ipsapirone and cannabidiol on human experimental anxiety. Journal of Psychopharmacoly, 7: 82-88.

27. Crippa JAS, Zuardi AW, Garrido GE et al. (2004). Effects of cannabidiol (CBD) on regional cerebral blood flow. Neuropsychopharmacology, 29: 417-426.

28. Lipska BK \& Weinberger DR (2000). To model a psychiatric disorder in animals: schizophrenia as a reality test. Neuropsychopharmacology, 23: 223-239.

29. Gardner DM, Baldessarini RJ \& Waraich P (2005). Modern antipsychotic drugs: a critical overview. Canadian Medical Association Journal, 172: 1703-1711.

30. Baldessarini RJ \& Tarazi FI (1996). Brain dopamine receptors: a primer on their current status, basic and clinical. Harvard Review of Psychiatry, 3: 301-325.

31. Hoffman DC \& Donovan H (1995). Catalepsy as a rodent model for 
detecting antipsychotic drugs with extrapyramidal side effects. Psychopharmacology, 120: 128-133.

32. Zuardi AW, Rodrigues JA \& Cunha JM (1991). Effects of cannabidiol in animal models predictive of antipsychotic activity. Psychopharmacology, 104: 260-264.

33. Malhotra AK, Adler CM, Kennison SD et al. (1997). Clozapine blunts $\mathrm{N}$-methyl-D-aspartate antagonist-induced psychosis: a study with ketamine. Biological Psychiatry, 42: 664-668.

34. Moreira FA \& Guimarães FS (2005). Cannabidiol inhibits the hyperlocomotion induced by psychotomimetic drugs in mice. European Journal of Pharmacology, 512: 199-205.

35. Robertson GS \& Fibiger HC (1992). Neuroleptics increase c-Fos expression in the forebrain: contrasting effects of haloperidol and clozapine. Neuroscience, 46: 315-328.

36. Zuardi AW, Guimarães FS, Guimarães VM et al. (2002). Cannabidiol: possible therapeutic application. In: Grotenhermen F, Russo E \& Varo RN (Editors), Cannabis and Cannabinoids: Pharmacology, Toxicology and Therapeutic Potential. The Haword Interactive Healing Press, New York, 359-369.

37. Guimarães VMC, Zuardi AW, Del Bel EA et al. (2004). Cannabidiol increases Fos expression in the nucleus accumbens but not in the dorsal striatum. Life Sciences, 75: 633-638.

38. Zuardi AW \& Guimarães FS (1997). Cannabidiol as an anxiolytic and antipsychotic. In: Mathre ML (Editor), Cannabis in Medical Practice. McFarland \& Company, Inc., Jefferson, NC, USA, 133141.

39. Consroe P, Laguna J, Allender J et al. (1991). Controlled clinical trial of cannabidiol in Huntington's disease. Pharmacology, Biochemistry, and Behavior, 40: 701-708.

40. Moreau JJ (1845). Du Hachisch et de l'Alienation Mentale: Etudes Psychologiques. Librarie de Fortin Mason, Paris, France (English edition: Raven Press, New York, 1972).
41. D'Souza DC, Perry E, MacDougall L et al. (2004). The psychotomimetic effects of intravenous delta-9-tetrahydrocannabinol in healthy individuals: Implications for psychosis. Neuropsychopharmacology, 29: 1558-1572.

42. Rottanburg D, Robins AH, Ben-Aire $O$ et al. (1982). Cannabisassociated psychosis with hypomaniac feature. Lancet, 2: 13641366.

43. Schneider U, Borsutzky M, Seifert J et al. (2002). Reduced binocular depth inversion in schizophrenic patients. Schizophrenia Research, 53: 101-108.

44. Leweke FM, Schneider U, Radwan M et al. (2000). Different effects of nabilone and cannabidiol on binocular depth inversion in man. Pharmacology, Biochemistry, and Behavior, 66: 175-181.

45. Krystal JH, Karper LP, Bremner JD et al. (1994). Subanesthetic effects of the noncompetitive NMDA antagonist, ketamine, in humans. Archives of General Psychiatry, 51: 199-214.

46. Bosi DC, Hallak JEC, Dursun SM et al. (2003). Effects of cannabidiol on (s)-ketamine-induced psychopathology in healthy volunteers. Journal of Psychopharmacology, 17 (Suppl): A55.

47. Zuardi AW, Morais SL, Guimarães FS et al. (1995). Anti-psychotic effect of cannabidiol. Journal of Clinical Psychiatry, 56: 485-486.

48. Zuardi AW, Hallak JEC, Dursun SM et al. (2006). Effect of cannabidiol in non responsive schizophrenia. Journal of Psychopharmacology (in press).

49. Leweke FM, Koethe D, Gerth CW et al. (2005). Cannabidiol as an antipsychotic: a double-blind, controlled clinical trial on cannabidiol vs amisulpride in acute schizophrenics. 2005 Symposium on the Cannabinoids, Burlington, Vermont, International Cannabinoid Research Society. http://CannabinoidSociety.org.

50. Ashton CH, Moore PB, Gallagher P et al. (2005). Cannabinoids in bipolar affective disorder: a review and discussion of their therapeutic potential. Journal of Psychopharmacology, 19: 293-300. 